ARTICLE

\title{
The Advancement of Radiological Risk Management in Reactor TRIGA PUSPATI (RTP): An Overview
}

\author{
Syahirah ABDUL RAHMAN*, Mohamad Azman CHE MAT ISA, Mohd. Zaid MOHAMED, \\ Phongsakorn A/L PRAK TOM, Shaiful Rizaide MOHD YAKIN, Shaharum RAMLI, \\ Wan Abd Hadi WAN ABU BAKAR and Mohamad Puad B. HJ ABU, Ir. Dr.
}

Nuclear Power Division, Malaysian Nuclear Agency, Bangi, 43000, Kajang, Selangor, Malaysia.

\begin{abstract}
Radiological Risk Management is an important method to be implemented in the RTP in the early stages of radiation control. The goal is to reduce exposure to radiation and to avoid undesirable risk because of the exposure from happening. This paper outlines the evolution of the Radiological Risk Management that was-implemented and adopted in the RTP and the advantages gained when it is implemented. In addition, this paper also describes in detail how the relationship between the dose-risk and measures to develop risk management is to ensure it is dealt with more systematically and responsibly. Finally, how the framework established and implemented is also outlined in this paper.
\end{abstract}

\section{KEYWORDS: Radiological Risk Management, RTP, framework Radiological Risk Management}

\section{Introduction}

Radiological Risk Management is an important method to be implemented in the Reactor TRIGA PUSPATI (RTP) in the early stages of radiation control. The history of radiological protection will be segregate into two eras ${ }^{1)}$. 1st era is parallel to the development of medical application of radiation. It started from the beginning of 20th century. The radiological protection was developing by protection against the severe effects of radiation (or called deterministic effects) cause by exposure to high doses. As we know, the deterministic effects are associated with much higher levels of radiation exposure, usually incurred over a much shorter period of time (fractions of a second to tens of days). Deterministic effects have two distinct features: 1) there is a threshold radiation dose, below which the deterministic effects are not observed; 2) the severity of the deterministic effect increases with the magnitude of the radiation dose. There are a variety of deterministic effects that can be observed after an acute exposure to radiation. These include (in order of increasing severity): 1) Hemopoietic syndrome an effect related to the effects of radiation on blood-forming tissues, normally indicated by changes in blood cell counts; 2) Gastrointestinal syndrome - an effect signalling the destruction of the gastrointestinal epithelium (the lining of the gastrointestinal tract); 3) Central nervous system syndrome an effect seen at very high radiation doses in which the central nervous system undergoes irreparable damage.

The 2nd era is parallel to the development of military and industrial applications of atomic energy and it started during the second half of the 20th century. It was dominated by the stochastic effects of the radiation. Stochastic effects are usually associated with exposures to low levels of radiation

*Corresponding Author, Email:syahirah@nuclearmalaysia.gov.my (C) 2012 Atomic Energy Society of Japan, All Rights Reserved over a long period of time (e.g. years). The term stochastic literally means 'random', the implication being that low levels of radiation exposure are not certain or guaranteed to produce an effect. The induction of cancer and genetic defects are two of the most familiar consequences attributed to stochastic effects. The description of stochastic effects is subject to a degree of controversy (owing to the difficulties in separating the effects of low-level radiation exposure from the effects of other carcinogens, e.g. tobacco smoke, non-radioactive species, etc), but the currently accepted theories lead to the following conclusions about stochastic effects: 1) There is no threshold level of radiation exposure below which we can say with certainty that cancer or genetic effects will NOT occur. 2) Doubling the radiation dose doubles the probability that a cancer or genetic effect will occur.

The latter, which appear in random fashion among the subjects of an exposed population, occur much later after the exposure: a few years for leukaemia, or even several tens of years for other cancers and possible hereditary effects ${ }^{2}$. Beyond the fact that it is impossible to predict which subjects will develop these effects within a population that has been exposed, the main question that remains, is concerns on the dose levels at which they are liable to occur. Faced with the impossibility of demonstrating the existence of a threshold for stochastic effects, radiological protection, from the 1940s on, has prudently been structured on the assumption that exposed subjects incur a risk whatever their level of exposure.

\section{Background of Reactor TRIGA PUSPATI (RTP)}

The PUSPATI TRIGA reactor (RTP) is kind of a pool built on ground level. TRIGA means Training, Research, Isotope Production \& General Atomic. This reactor is designed to give good stability in the experimental work in 
the reactors. Core is 5 meters below the surface of the reactor tank water. RTP has been used as the standard fuel elements and fuel element is a combination of Uranium in Zirconium Hydrate homogenous and placed in containers made of Stainless steel. Subsequently, the fuel elements have been arranged in six rings in the core so that the RTP secular is in good condition ${ }^{3)}$. Summary description and diagram of the RTP reactor as shown in Table $\mathbf{1}$ below:

Table 1 Characteristics of the RTP.

\begin{tabular}{|c|c|}
\hline Items & Detail \\
\hline Name & 1 MW TRIGA MARK II Research Reactor \\
\hline Purpose & $\begin{array}{l}\text { Research in Nuclear Physic, Radiation } \\
\text { Chemistry, Biology, } \\
\text { Isotope Production, Research for Shielding \& } \\
\text { for Trainings }\end{array}$ \\
\hline Type & Pool type \\
\hline First reached Criticality & 28 June 1982 \\
\hline Max Thermal Power & $\begin{array}{l}1 \text { MWth (steady state, square wave modes) } \\
1360 \text { MW (Modes Pulsing) }\end{array}$ \\
\hline Average Power Density & $22.8 \mathrm{~W} / \mathrm{cm} 3$ \\
\hline $\begin{array}{l}\text { Max Thermal Neutron } \\
\text { Flux }\end{array}$ & $1 \times 1013 \mathrm{n} / \mathrm{cm} 2 / \mathrm{s}$ \\
\hline $\begin{array}{l}\text { Shape \& Size of reactor } \\
\text { core }\end{array}$ & Cylindrical (110 cm x $89 \mathrm{~cm} \mathrm{H})$ \\
\hline Coolant \& Moderator & Demineralised Light Water \\
\hline Core Cooling & Natural Convection \\
\hline Heat rejection & Two-loop cooling system \\
\hline Control Rod & Boron Carbide, B4C \\
\hline Reflector & Graphite \\
\hline Shape of Fuel Element & Rod type \\
\hline Fuel Pellet & Uranium Zirconium Hydride (U-ZrH1.6) \\
\hline Fuel Clad & Stainless Steel 304 \\
\hline Enrichment of U.235 & Approx. $20 \%$ \\
\hline Fuel Element Weight \% & $8.5 \%, 12 \%, 20 \%$ \\
\hline
\end{tabular}

\section{Ionizing Radiation at RTP}

In the RTP, the Ionizing Radiation such as Gamma, Beta, Alpha and fission (electron, proton and neutron particles) are produced during operation of the RTP. This radioactivity is a natural and spontaneous process by which the unstable atoms of an element emit or radiate excess energy in the form of particles or waves. These emissions are collectively called ionizing radiation. Depending on how the nucleus loses this excess energy, a lower energy atom of the same form or a completely different nucleus and atom can be formed.

Ionization is a particular characteristic of the radiation produced when radioactive elements decay. These radiations are of such high energy that when they interact with materials, they can remove electrons from the atoms in the material. This effect is the reason why ionizing radiation is hazardous to health, and provides the means by which radiation can be detected.

In the reactor, the neutrons are produced through the chain fission reaction of Uranium-235 nuclei in the fuel elements. The fuels contain $20 \%$ enriched uranium-235. This enrichment is necessary as the abundance of uranium-235 in nature is less than $1 \%$. The enrichment will provide the required quantity of uranium-235 to sustain the chain reaction of the uranium-235 fissions.

The uranium-235 nucleus absorbs a neutron to split into two new nuclei along while also producing an average of two fast neutrons with energies of $10 \mathrm{MeW}$. The neutrons collide with water molecules and lose energy or thermalise to energies in the range of 0 to $0.025 \mathrm{eV}$ before being absorbed by another two uranium-235 nuclei to propagate the chain reaction.

During the chain reaction, neutrons may leak out or be absorbed by other materials in the reactor. Hence, in designing the reactor, materials are chosen to take into account the above consideration. In the TRIGA reactor, high purity graphite surrounding the core acts as a neutron reflector while an americium beryllium source provides the initial neutrons to start-up the reactor power.

Water that has been stripped of its minerals is used to moderate the high energy neutrons, dissipate heat and prevents radioactive nitrogen-16 from reaching the water surface before it fully decays. Nitrogen-16 with a half-life of 7.13 seconds is produced when dissolved oxygen-16 molecules in the reactor core interact with the neutrons. In addition, surrounding the aluminium reactor tank is a 2.5 meter thick high density concrete shielding the reactor environment from being contaminated by radioactive emitted from the reactor core. The chain fission reaction of Uranium-235 as shown in Figure $\mathbf{1}$ below:

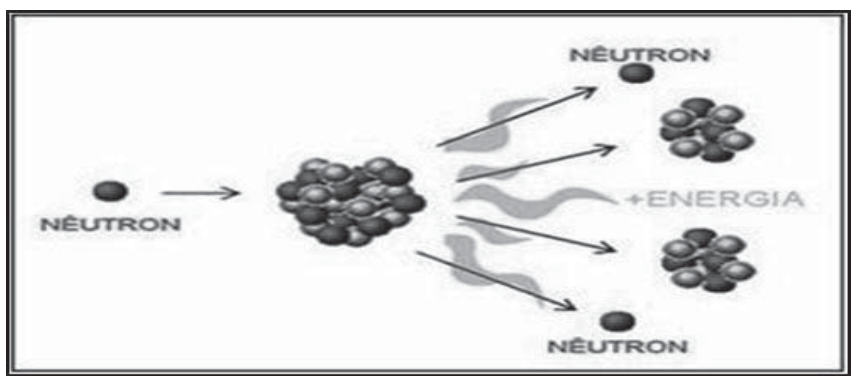

Fig. 1 Chain Fission Reaction of Uranium-235.

\section{Principal of Radiological Risk Management (RRM) at RTP}

The objective of Radiological Risk Management (RRM) implemented at RTP is for the protection of workers/personnel and user from unnecessary radiation exposure before, during and after operation at reactor without eliminating the beneficial application of radiation and radioactive materials ${ }^{4)}$. The main aim is to prevent deterministic effects and limit the probability of stochastic effect to acceptable level. The three principles $^{5,6}$ used in radiation protection systems are:

\section{Justification of a practice}

Justification of a practice where no practice involving ionizing radiation shall be adopted unless its introduction produces a net positive benefit and no other alternative technique or the radiation technique is superior than other techniques (e.g.: Screening of workers).

\section{Optimization of dose-ALARA principle}

It was a key component of the system that all necessary exposures be kept As Low As Reasonably Achievable. The concept of 'ALARA' and 'optimization of protection' are identical. Other techniques implemented are choices of materials and equipment, choice of specific technique and working procedures, use of personnel protective equipment (PPE), proper monitoring system and proper engineering, administrative control etc. 


\section{Dose Limitation}

Dose limit is used to apply controls on each individual's accumulation of dose and is not a demarcation between "safe" and "dangerous", Dose limit is apply for occupational exposure only, excluding dose received from natural radiation and medical exposure. Dose limits are similar for men and women except pregnant women.

\section{Evolution of the Radiological Risk Management (RRM) at RTP}

In the early establishment of the RTP (1982), RTP was managed by the Technical Services Program under the Technical Support Department. This section has twelve sections under it where the Reactor Facilities are the section responsible for managing the $\mathrm{RTP}^{7,8)}$. After 26 years managing the RTP, Malaysian Nuclear Agency had transformated /restructure the organization. The Technical Support Division now no longer responsible in managing the RTP. Figures 2 and $\mathbf{3}$ below shows the frameworks/Organizational Structure of Malaysian Nuclear Agency management for early 1982 to 2008.

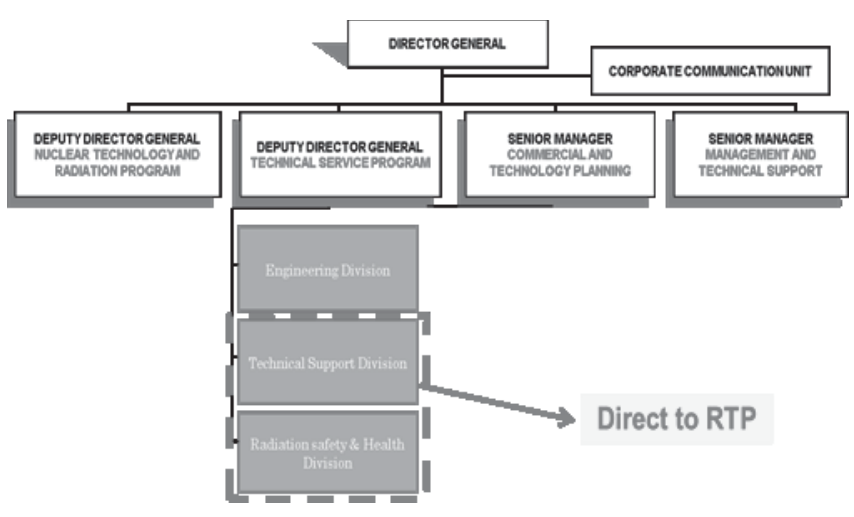

Fig. 2 Organizational Structure of Malaysian Nuclear Agency.

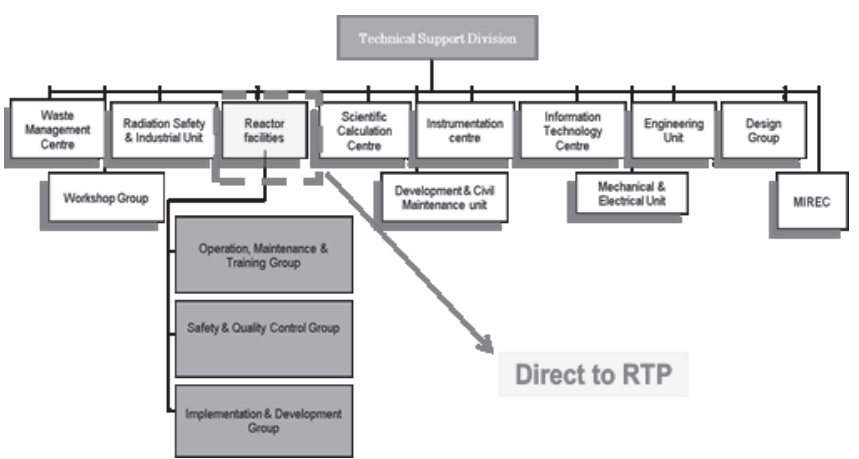

Fig. 3 Organizational Structure of Technical Support Division.

In 2008, the Technical Services Program has added a division known as the Nuclear Power Division (BKN). Nuclear Power Division (BKN) was established on $1^{\text {st }}$ April 2008 where it consists of six (6) Section, i.e. Section of Operations and Maintenance Reactor (O\&M), Section of Technology Assessment, Engineering and Safety Reactor (TES), Section of Physics nuclear and reactor (RXP), Section of Electronics, Instrumentation and Control Reactor (RIC), Section of Quality Assurance and Integrated Management System (QAS) and Section of nuclear Fuel Cycle
Management (FCM). Figures 4 and 5 below shows the frameworks/ Organizational Structure of Malaysian Nuclear Agency management on 2008 until present.

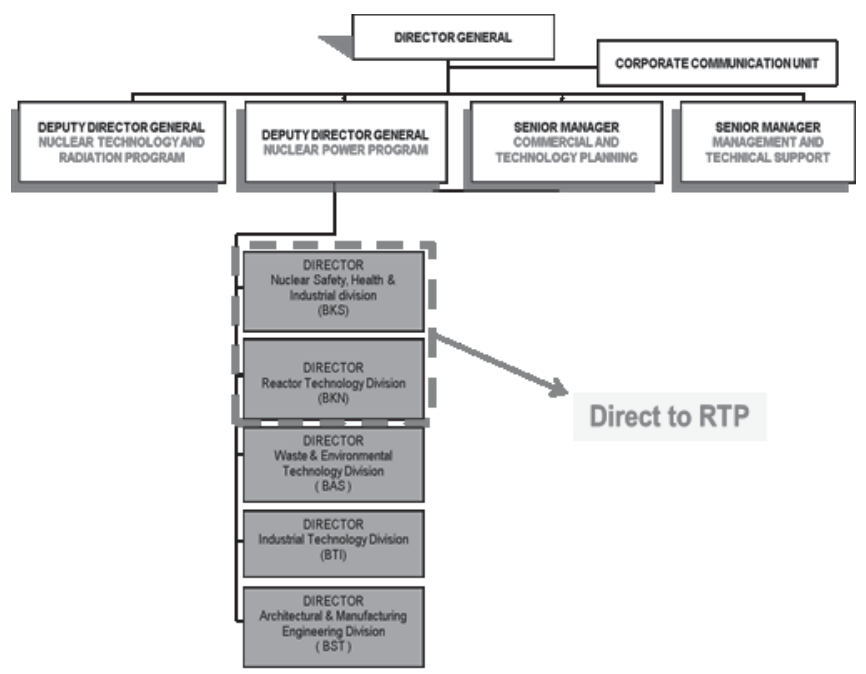

Fig. 4 Organizational Structure of Malaysian Nuclear Agency at present.

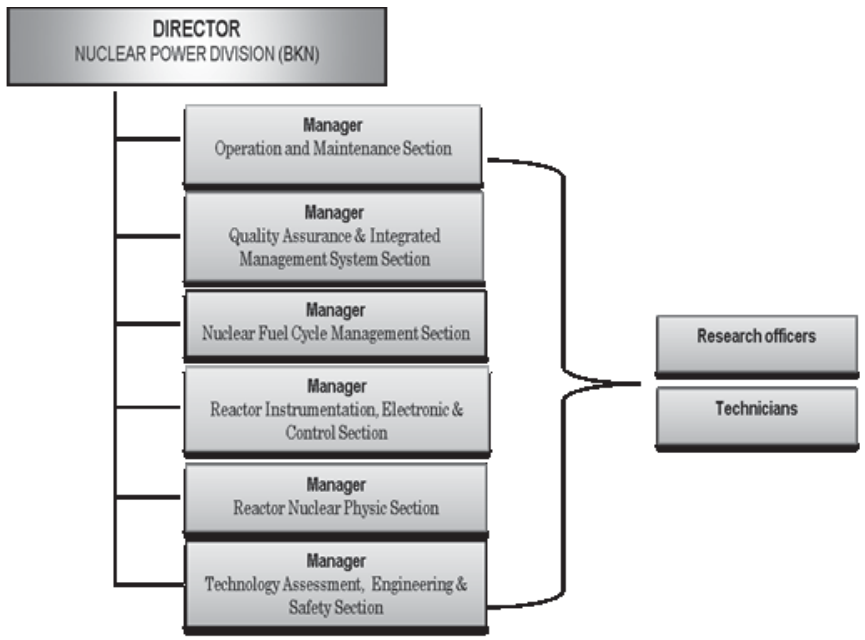

Fig. 5 Organizational Structure of Reactor Technology Division at present.

Radiological Risk Management is very important to be implemented to prevent workers from being exposed to radiation during the operation and maintenance activity/period. BKN is responsible to manage the radiological risk with the cooperation of other divisions.

Therefore, a workflow and organizational structure was designed to identify those responsible for operation and maintenance of the RTP.

Figure 6 shows the organisation structure of RRM carried out in the Malaysian Nuclear Agency. BKN is responsible directly for the operation and maintenance of the RTP. Other divisions such as; Nuclear Safety, Health \& Industrial division (BKS), Technical Support Division (BST) and Engineering Division (BKJ) is jointly or indirectly responsible in assisting in the management of RTP.

Safety Health \& Environmental Management System (SHE-MS) Steering Committee is the highest committee of 
Malaysian Nuclear Agency that communicates directly with the Director General. The main functions of the SHE-MS is;

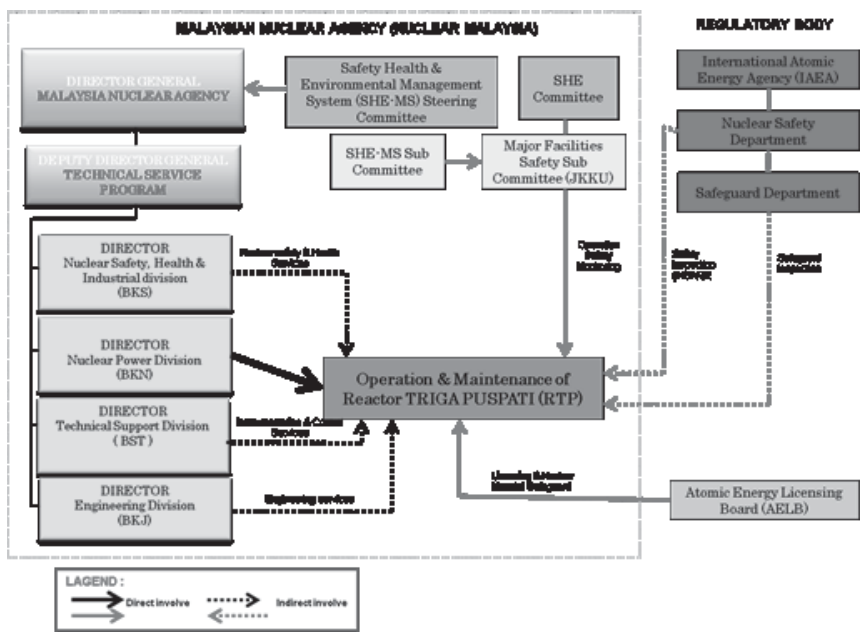

Fig. 6 Organisation structure of Radiological Risk Management (RRM) at RTP.

a) To evaluate, approve and control the implementation of all activities involving safety and health of workers, the public and the environmental conducted by the employee in Nuclear Malaysia. b) Give feedback to top management about the current status of safety at Nuclear Malaysia. Therefore, before the RTP can start to operate, BKN has to notify and make a report to the (SHE-MS) Steering Committee.

The Atomic Energy Licensing Board (AELB) was established on 1 February 1985, based on the Atomic Energy Licensing Act (Act 304) passed by the Parliament in April 1984. It was a serious initiative by Government of Malaysia to regulate, safeguard and monitor the ionizing radiation activities in Malaysia. Therefore, before the operations of RTP were carried out, license to operate the reactor must be obtained for any activity related to ionising radiation.

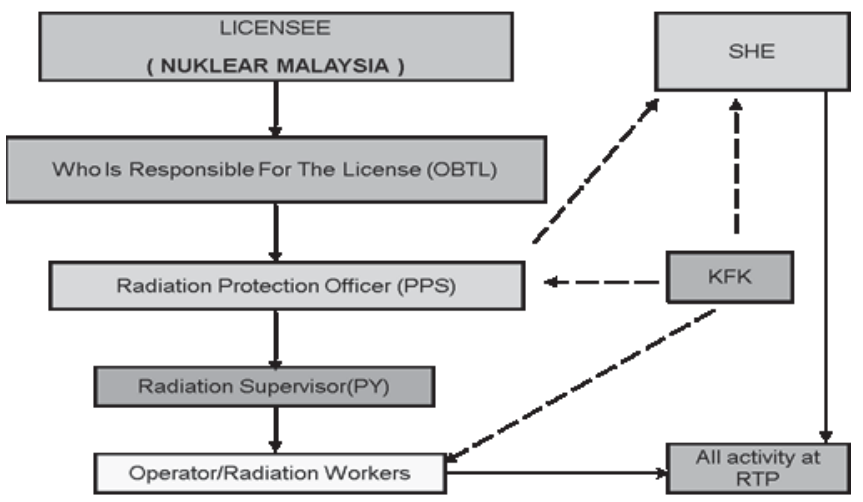

Fig. 7 Radiological Risk Management (RRM) workflow.

Individuals and groups who are involved in the management and implementation of radiation protection programs and activities in accordance with the Act 304 at Malaysian Nuclear Agency are as shown in Figure 7. The hierarchy of individuals saw the transfer of duties and responsibilities in the implementation of radiation protection programs and activities that need to be done in the Malaysian Nuclear Agency. Health Physic Group (KFK) from BKS (see Figure 8) acts as the secretariat for the SHE Committee as well as implementing the necessary radiation protection activities to the Radiation Protection Officer (PPS) and Radiation Worker. KFK also implements radiation protection programs and activities at Malaysian Nuclear Agency, while giving radiation protection and training services to workers and also to external worker who are working with radiation sources in the Nuclear Malaysian premises.

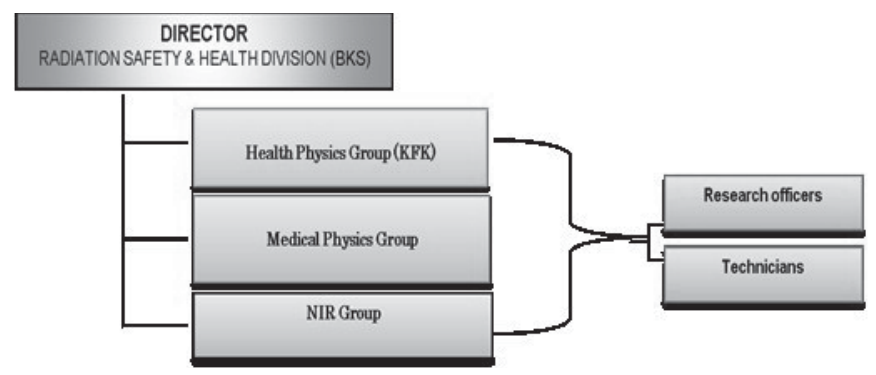

Fig. 8 Organizational Structure of Radiation Safety \& Health Division (BKS).

\section{Conclusion}

At the end of this review of the main aspects of radiological risk management, it is interesting to point out the proper management structure to develop risk management to ensure it is dealt with more systematically and responsibly.

The nuclear (power, military or research) reactors such as RTP are the main sources of radiation. The radioactivity of nuclear reactor core are millions times higher than any other man-made sources of radiation. The potential danger from an accident at a nuclear reactor is exposure to radiation.

The safety practice implemented at Malaysian Nuclear Agency is essential to ensure it is deal with more systematically and responsibly.

\section{Acknowledgments}

The authors would thank to Malaysian Nuclear Agency especially Nuclear Power Division (BKN) for their kind support of this study.

\section{References}

1) Quality Insurance Program (QAS), Program Pengurusan Penuaan Di RTP, NUKLEARMALAYSIA/L/2011/16

2) J Lochard and $C$ Schieber, The evolution of radiological risk management: an overview, 5 April 2000.

3) Lindell B 1996 History of radiation protection in the first 100 years Standing Conference on Health and Safetyin the Nuclear Age, 3rd Meeting (26-27 November) ( Luxembourg: European Commission)

4) Noriah Mod Ali, Evolution of Radiological Protection Trends-the Malaysian Perspective, Progress in NUCLEAR SCIENCE and TECHNOLOGY, Vol.1, p.14-19 (2011).

5) Kenneth Sheely, Office of Global Threat Reduction, U.S. Department of Energy, Nuclear and Radiological Risk Reductions: Program Management and Risk Mitigation on a Global Scale, July 11-15, 2010 Baltimore, MD, USA

6) William C. Inkret, Charles B. Meinhold, and John C. Taschner, $A$ Brief History of Radiation, Number 231995 Los Alamos Science

7) Website of Nuklear Malaysia, http://.nuclearmalaysia.gov.my.

8) Safety, Health And Environmental Management System (SHE MS), Pengurusan Keselamatan Radiologi Agensi Nuklear Malaysia, NM.SSP.13. 